\title{
Finite Element Analysis and Lightweight Design of Hydro Generator Lower Bracket
}

\author{
Yongyi Liao, ${ }^{1,2}$, Baiyu Liao ${ }^{1}$ \\ ${ }^{1}$ Key Laboratory of Vibration and Noise under Ministry of Education of Yunnan Province, Kunming 650500, \\ China. \\ ${ }^{2}$ Continuing Education College, Kunming University of Science and Technology, Kunming 650051, China. Email: \\ yongyiliao@163.com
}

Lower bracket is an important component in hydro generator. Taking lower bracket as the research object, the strength, the stiffness and the dynamic characteristics of lower bracket have been simulated and analyzed by means of establishing a finite element model. With the two design indexes of maximum normal stress and stiffness as the constraint conditions, aiming at an optimized design with the minimum mass and proposed a lightweight optimization method. The design parameters of the optimized model of hydro generator lower bracket are determined by using the compound form method with optimization iteration. Through lightweight optimization design, the maximum normal stress and maximum displacement of lower bracket are within the allowable value range, modal analysis shows that the dynamic characteristics of the optimized structure also meet the requirements, with the potential of material further utilized. The lightweight optimization design reduced the weight of lower bracket in hydro generator by $790 \mathrm{~kg}$ and the weight-loss ratio reaches $44.38 \%$, thus achieving the purpose of lightweight. The optimization results are applied in the improvement design of lower bracket and the method is practical and suitable for engineering applications.

Keywords: Hydro generator, Lower bracket, Finite element model, Lightweight design, Optimized model

\section{Introduction}

Water turbines are developing towards high water head, large capacity and structure lightweight [1]. With the increase of water turbine capacity and unit size, the requirement of structural lightweight is very prominent and urgent. Lower bracket is the main load bearing parts of water turbine and its design directly affects the overall performance of water turbine. Lower bracket is large and complex in shape, its lightweight demand is urgent. In addition to meeting various functions in its structure design, lower bracket should also be in ensuring the demand required by strength, stiffness and dynamic characteristics, and to realize the lightweight. Some progress has been achieved in structural optimization design and dynamic characteristics analysis of water turbine and its components in recent years [2]. The structural optimization design is mainly proceed with the shape, strength and stiffness of the corresponding parts [34]. Wang Bo et al. [5] optimized the structural size of water turbine bucket in high stress zone by using finite element method. The optimized results meet requirements of strength and structural hydraulic performance, and the damping tool holder with large length to diameter ratio for bucket processing was developed to ensure manufacturing accuracy. Zhao Daoli et al.
[6] applied finite element method to analyze the strength of the water turbine runner and proposed two design schemes to improve the stress of runner blade. Shao Guohui et al. [7] improved the design for flow passage components (spiral case, draft tube, runner etc.) of water turbine through CFD analysis, the analysis and test data meet the requirements of hydraulic design parameters. Based on traditional machine design method and the mechanical reliability design method, Qi Xueyi et al. [8] designed and calculated water turbine head cover, the comparison and analysis of the two methods are described. In terms of dynamic characteristics, the natural frequencies and vibration modal of structures are mainly analyzed, by increasing the lower-order natural frequencies, structural resonance is suppressed to avoid excitation frequencies [9]. By applying finite element method, Li Zhaojun established the dynamic equations of runner blade for the Francis turbine, obtained and derived the natural frequencies and resonance failure probability of runner blade, and the analysis is presented through an example [10]. Through establishing the nonlinear dynamic equation for main shaft system of water turbine, the method for nonlinear vibration reliability with multiple failure modes is analyzed and proposed, and an example is presented and calculated [11]. Yuan Xiaoming et al. [12] established the coupling model of stator, rotor and upper bracket of hydro generator, 
analyzed natural frequency and harmonic response of the model, and obtained the influences of the stiffness of rib and jack on the vibration amplitude.

The above researches focus on the performance optimization design and dynamic performance analysis of water turbine parts, and there are relatively few optimization designs for lightweight objective. Based on the study of head cover, upper bracket and stator of Francis turbine in an electrical machinery plant [1315], taking the lower bracket as research object, and establishinged its finite element model according to the actual size and working condition, the strength, the stiffness and the dynamic characteristics are simulated and analyzed. Based on structural optimization design principles [16-17], with the two design indexes of maximum normal stress and stiffness, the lightweight objective optimization methods are proposed and described.

\section{Finite element model and equivalent load calculation of lower bracket}

The lower bracket is mainly composed of upper ring, lower ring, housing and rib plate. Lower bracket is equipped with hydraulic cylinder, lower guide bearing, etc., which is fixed on the concrete foundation by bolts of support arm. Bolts connect its main part and support arm, which is convenient for installation and maintenance. Lower bracket is made of carbon structural steel Q235B with different thickness. The structure diagram is shown in Fig. 1.

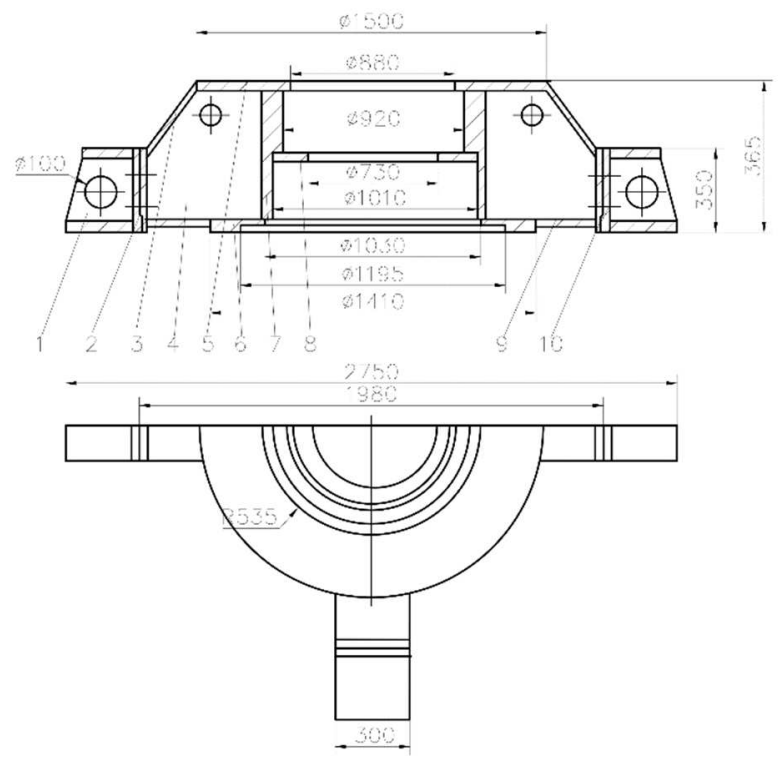

1-Support arm; 2,3,9-Bearing plate; 4-Rib plate; 5-Upper ring; 6-Lower ring; 7-Housing; 8-Retainer ring; 10-Bolt

Fig. 1 Structure diagram of lower bracket

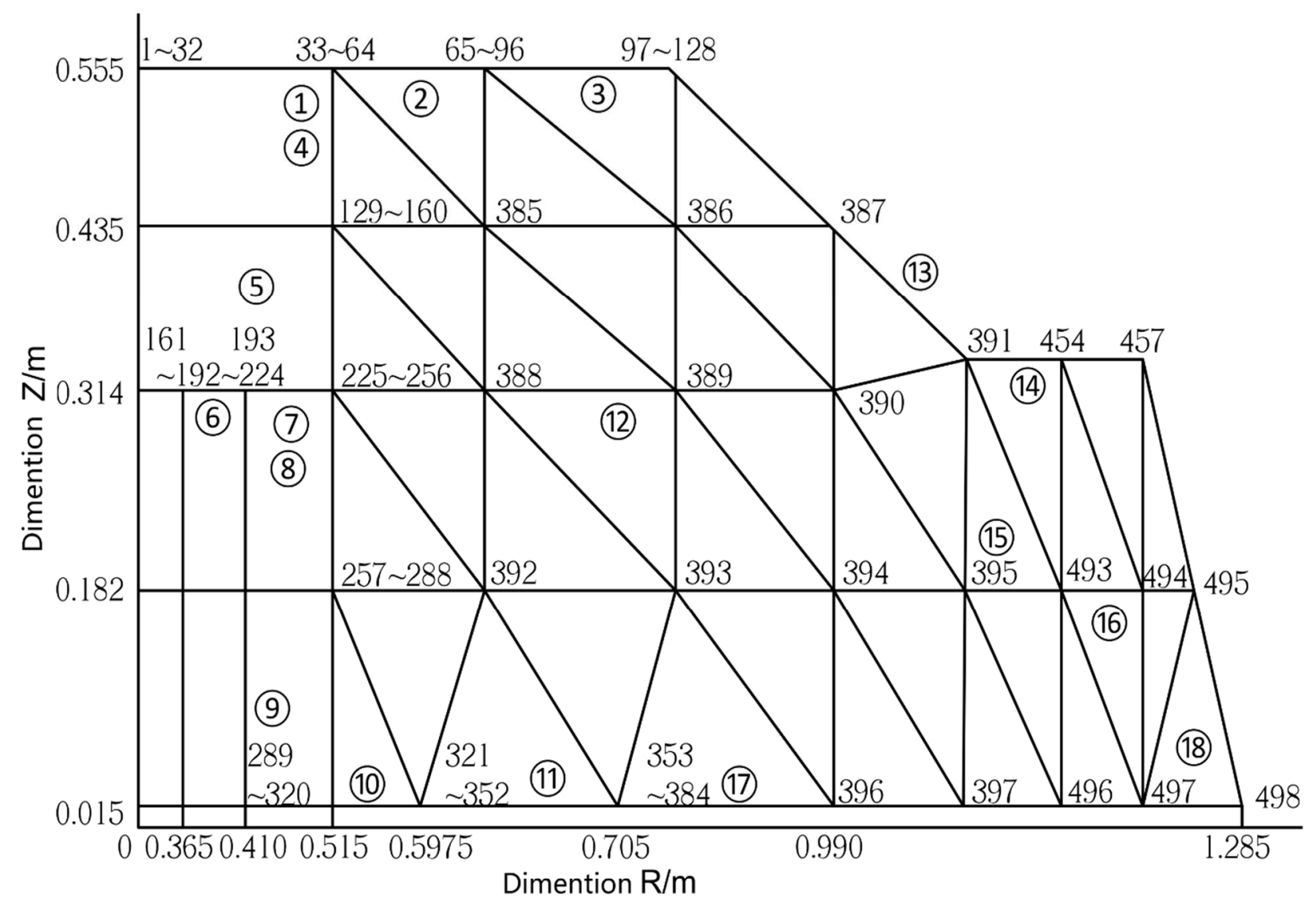

Fig. 2 Finite element discrete model of lower bracket 
Lower bracket is a complex structure of plate box body. As three-dimensional triangular shell element can be accurately classified complex three-dimensional structures, it is composed of plane stress membrane element and plate bending element, thus bending and shear force can be transferred, its mechanical characteristics is closer to force status of lower bracket. Therefore, three-dimensional triangular shell element is used as element of finite element model for lower bracket structure. The finite element discrete model of lower bracket is shown in Fig. 2. The entire finite element model consists of 18 element groups, 1036 elements, 548 nodes, and 3288 degrees of freedom. The finite element model is shown in Fig. 3.

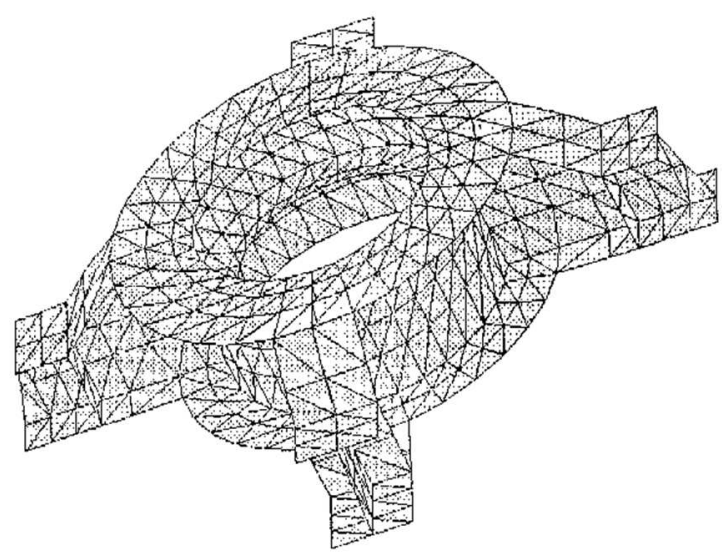

Fig. 3 Finite element model of lower bracket

There are many kinds of loads acting on lower bracket structure, and the loads are complex and related to the operating state of hydro generator. In general, lower bracket bears these loads: (1)The gravity of the rotating part of hydro generator set; (2)weight of lower bracket; (3)Thrust from the hydraulic cylinder at generator start. The gravity of the rotating part of hydro generator set is about $450 \mathrm{kN}$, and the weight of lower bracket is about $17.5 \mathrm{kN}$. The gravity of the rotating part is evenly distributed on the pistons of four hydraulic cylinders, and the load borne by each piston is evenly distributed on 9 nodes of contact surface of hydraulic cylinder and upper ring. Therefore, 36 nodes bear the external load, and the load borne by each node is equal, which is $13 \mathrm{kN}$.

\section{Lightweight optimization design method and mathematical model of lower bracket}

Structure optimization problems are generally divided into three categories[16], namely size optimization, shape optimization and topology optimization. The design variables of size optimization are the sizes of a certain type of structure (such as crosssectional area, plate thickness, etc.). The design varia- bles of shape optimization represent the shape or contour of the design domain, and a set of partial differential equations are used to describe its state. Topology optimization is the advanced form of structure optimization; the design variables have a larger design space and more freedom, which is still on the stage of primary research [18]. The main difficulty is the structures of realizing structure functional requirements have an infinite variety of forms, and these topological forms is difficult to be quantitatively described and parameterized, which limit the topology optimization modeling and practical application. Because of the complex mathematical description of structure boundary, shape optimization is not widely used in practical structure optimization design. Sizing optimization involves the control of structural parameters, which is usually concluded more specific and easy to apply in structural improvement design and lightweight design. It is practical and suitable for engineering application.

Based on sizing optimization design principle $[16,17,19]$, in the lightweight design of lower bracket, considering that the overall structure size of the lower bracket, such as the installation and mating dimensions, cannot be changed, 14 kinds of plate thicknesses of lower bracket structure are selected as design variables, which denote as

$$
\boldsymbol{X}=\left[x_{1}, x_{2}, \cdots \cdots x_{14}\right]^{\mathrm{T}}
$$

The mass of lower bracket $W(\boldsymbol{X})$ is taken as the objective function of optimization design; the structural dimensions other than plate thickness establish its expression, that is

$$
\begin{aligned}
W(\boldsymbol{X})= & 7850\left(1.158 x_{1}+0.719 x_{2}+0.1095 x_{3}\right. \\
& +0.305 x_{4}+0.967 x_{5}+0.288 x_{6}+0.439 x_{7} \\
& +0.924 x_{8}+0.384 x_{9}+0.24 x_{10}+0.3936 x_{11} \\
& \left.+0.3247 x_{12}+0.342 x_{13}+0.354 x_{14}\right)
\end{aligned}
$$

With conforming to strength and stiffness of lower bracket as the constraint conditions, namely, the maximum stress and the maximum displacement of nodes in each element group of the structure are less than the allowable values, that is

$$
\begin{cases}\sigma_{i} \leq\left[\sigma_{i}\right] & i=1,2, \cdots, p \\ \delta_{j} \leq\left[\delta_{j}\right] & j=1,2, \cdots, h\end{cases}
$$

In above equation, $\left[\sigma_{i}\right]$ is allowable stress of element group $i,\left[\delta_{j}\right]$ is allowable displacement of node $j$.

Then, the mathematical model of lower bracket lightweight optimization design is obtained as

$$
\left\{\begin{array}{c}
\min W(\boldsymbol{X}) \\
\text { s.t. }\left\{\begin{array}{c}
\sigma_{i} \leq\left[\sigma_{i}\right] \quad i=1,2, \cdots, p \\
\delta_{j} \leq\left[\delta_{j}\right] \quad j=1,2, \cdots, h
\end{array}\right. \\
\boldsymbol{X}=\left[x_{1}, x_{2}, \cdots, x_{14}\right]^{\mathrm{T}}
\end{array}\right.
$$




\section{Comparative analysis of lightweight de- sign solution of lower bracket}

Tab. 1 Optimization design results of lower bracket

\begin{tabular}{llll}
\hline $\begin{array}{l}\text { Design } \\
\text { variables }\end{array}$ & $\begin{array}{l}\text { Original } \\
\text { value } / \mathrm{m} \\
\mathrm{m}\end{array}$ & $\begin{array}{l}\text { Optimal } \\
\text { value } / \mathrm{m} \\
\mathrm{m}\end{array}$ & $\begin{array}{l}\text { Standard- } \\
\text { ized } \\
\text { value } / \mathrm{mm}\end{array}$ \\
\hline$x_{1}$ & 20 & 12.395 & 15.00 \\
$x_{2}$ & 60 & 48.59 & 50.00 \\
$x_{3}$ & 15 & 3.198 & 6.00 \\
$x_{4}$ & 15 & 7.198 & 10.00 \\
$x_{5}$ & 20 & 12.395 & 15.00 \\
$x_{6}$ & 20 & 6.796 & 10.00 \\
$x_{7}$ & 25 & 12.379 & 15.00 \\
$x_{8}$ & 20 & 6.796 & 10.00 \\
$x_{9}$ & 15 & 6.796 & 10.00 \\
$x_{10}$ & 20 & 10.796 & 12.00 \\
$x_{11}$ & 50 & 33.59 & 36.00 \\
$x_{12}$ & 20 & 6.796 & 10.00 \\
$x_{13}$ & 20 & 6.796 & 10.00 \\
$x_{14}$ & 25 & 13.395 & 15.00 \\
\hline
\end{tabular}

Tab. 2 Comparison of dynamic characteristics of lower bracket

\begin{tabular}{ccc}
\hline Performance parameters & Original model & Optimized model \\
\hline Maximum displacement $/ \mathrm{mm}$ & 0.0823 & 0.243 \\
Node number & 72 & 66 \\
Maximum stress $/ \mathrm{MPa}$ & 32.5 & 94.6 \\
Element group number & 13 & 2 \\
\hline First order natural frequency $/ \mathrm{Hz}$ & 306.41 & 185.09 \\
Second order natural frequency $/ \mathrm{Hz}$ & 345.42 & 188.43 \\
Third order natural frequency $/ \mathrm{Hz}$ & 350.24 & 188.48 \\
Fourth order natural frequency $/ \mathrm{Hz}$ & 350.34 & 191.41 \\
\hline Structure mass $/ \mathrm{kg}$ & 1780 & 990 \\
Reduce weight $/ \mathrm{kg}$ & & 790 \\
Weight loss ratio & & $44.38 \%$ \\
\hline
\end{tabular}

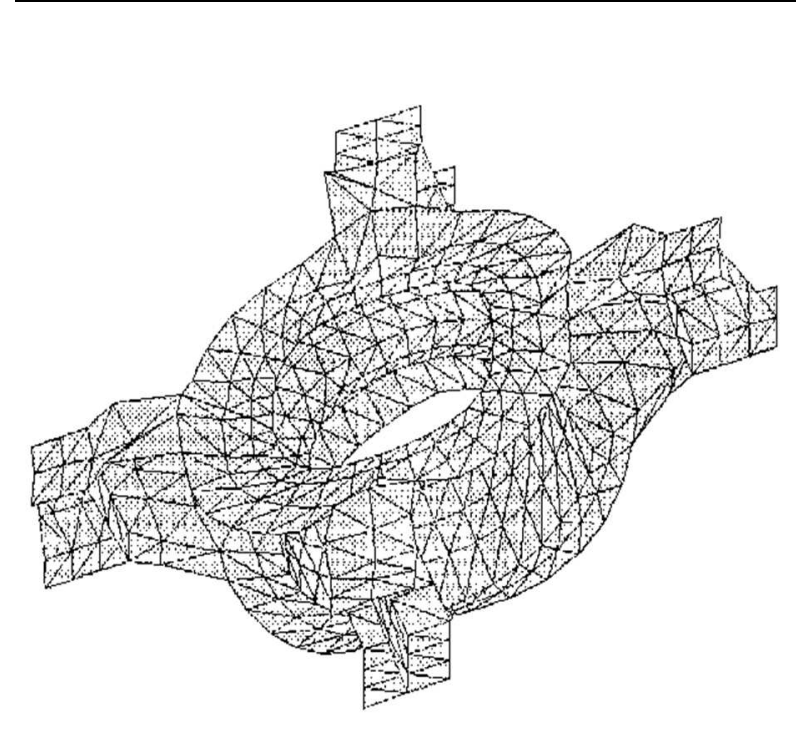

Fig. 4 Static deformation of Original model
According to the mathematical model of lower bracket lightweight optimization design, with the objective of lightweight design and conforming to strength and stiffness as the constraint conditions, lower bracket structure is analyzed and calculated by using the compound form method with optimization iteration. The compound form method is developed from simplex method, which overcomes the dimensionality reduction of easy to occur in simplex method, its shape does not need to keep regular form, and there is no special requirement on the properties of objective function and constraint conditions. Every time the shape of the compound shape is changed, it is closer to the optimal point. After repeated iteration until the best approximation, the lightweight optimization results of lower bracket are obtained, as shown in Tab. 1.

The maximum stress, strain, structural deformation and natural frequencies for original and improved finite element model under loads are simulated and calculated respectively. The comparative results are shown in Tab. 2. The corresponding static deformations of lower bracket are shown in Fig. 4 and Fig. 5.

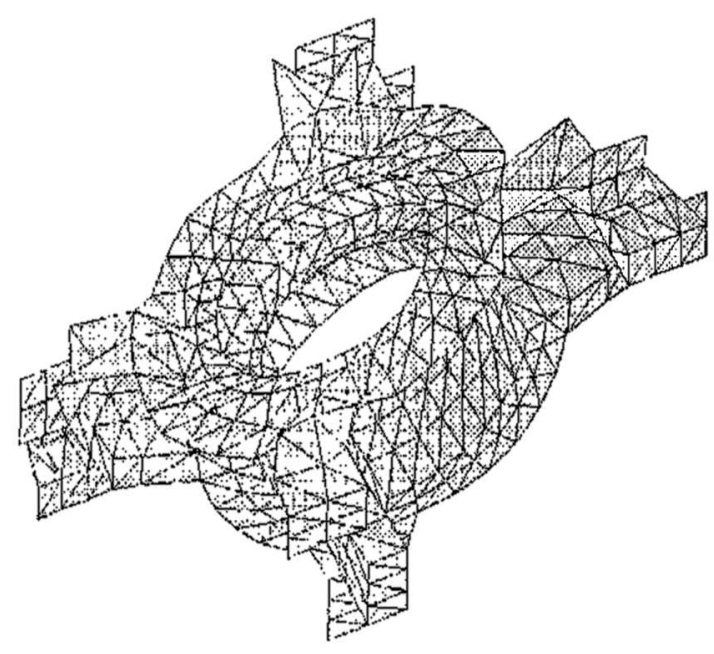

Fig. 5 Static deformation of Optimized model 
The maximum displacement of the original model occurs at the 72 node, and the maximum displacement is $\delta_{\max }=0.0823 \mathrm{~mm}$. The maximum stress occurs in the 13 group, whose value is only $\sigma_{\max }=32.5 \mathrm{MPa}$. The material has not been fully utilized and the lightweight space is larger.

In order to verify the correctness and validity of the finite element model, the original structure and the optimized structure are tested by hammer impulse exciting, and the special hammer for excitation was developed. The test data are analyzed by signal processor 7T17S, and the modal parameters of lower bracket are identified. The modal frequencies and modes of the first four orders were in well agreement with the natural frequencies and modes calculated by the model. The finit element model established well simulates the actual structure, the computed results agree with that of exciting test and modal analysis.

Through the lightweight optimization design, the plate thicknesses of lower bracket are obviously reduced, the weight of lower bracket structure is reduced by $790 \mathrm{~kg}$, and the weight loss rate is up to $44.38 \%$. In the optimal solution, the mass of lower bracket is only $W\left(X^{*}\right)=849 \mathrm{~kg}$, reduced by $931 \mathrm{~kg}$, weight loss rate reached $52.3 \%$, and weight loss effect is obvious. The maximum stress and maximum displacement of lower bracket after optimization are both within the allowable value range. Modal analysis shows that the dynamic characteristics of optimized structure meet requirements. The first order natural frequency $185.09 \mathrm{~Hz}$ is still much higher than the runaway frequency $16.04 \mathrm{~Hz}$ of hydro generator and there is no resonance after the lightweight design.

The optimization results have been applied in lower bracket improvement design of the plant. After full load operation and site test, the dynamic characteristics of lower bracket fully meet the requirements and achieve satisfactory economic benefits.

\section{Conclusions}

1. A finite element simulation model was established to simulate the working condition according to the actual size of lower bracket, which is the basis of strength and stiffness analysis and lightweight optimization design.

2. With the maximum normal stress and stiffness of lower bracket as constraint conditions, and lightweight design as the objective, based on mathematical model of lightweight optimization design, the lightweight optimization results of lower bracket are obtained and applied in the improvement design. The finite element model established well simulates the actual structure, the computed results agree with that of exciting test and modal analysis. The method is practical and suitable for engineering applications.

3. The lightweight design effectively reduce the weight of lower bracket of hydro generator, and the maximum stress, maximum displacement and dynamic characteristics meet the design and use requirements.

\section{Acknowledgements}

This work was supported by National Natural Science Foundation of China grants program (61863016) and Yunnan province science and technology plan project (S2016DC069).

\section{References}

[1] YANG H., LIU G., LIU Y., et al. (2014). The current research and development analysis of condition monitoring for hydroelectric generating units. In: Journal of China Institute of Water Resources and Hydropower Research, Vol. 12, No. 3, pp. 300-305.

[2] GUSTAVSSON R. K., AIDANPÄÄ J. O. (2009). Evaluation of impact dynamics and contact forces in a hydropower rotor due to variations in damping and lateral fluid forces. In: International Journal of Mechanical Sciences, Vol. 51, No. 9, pp. 653-661.

[3] Sutasn T., Arkarapon S., Wiriyakorn P. (2017). Finite element analysis of counterbore-shaped parts by using sheet-bulk metal forming process. In: Manufacturing Technology, Vol. 17, No. 4, pp. 597-602.

[4] Jan M., Stefan G., Martin P. et al. (2019). Optimization of the runner numerical design dimensions using the simulation program. In: Manufacturing Technology, Vol. 19, No. 2, pp. 273-279.

[5] WANG B., LIU X.L., LIU J. S., et al. (2015). Structural optimization and manufacturing for region of high stress of pelton turbine. In: Journal of Mechanical Engineering, Vol. 51, No. 21, pp.148-155.

[6] ZHAO D. L., WANG H. Y., WU Z. J., et al. (2015). Research on rigidity \& strength analysis of Francis runner and improvement measures. In: Journal of Mechanical Strength, Vol. 37, No. 4, pp. 748-753.

[7] SHAO G. H., WANG Q. Y. (2013). Optimization design of the high specific speed Francis turbine of Zangmu power station. In: Water Sciences and Engineering Technology, No. 3, pp. 51-56.

[8] QI X. Y., LI C. C., ZHNG X. J., et al. (2008). The reliability design and calculation of hydraulic turbine head cover. In: Large Electric Machine and Hydraulic Turbine, No. 2, pp. 40-43. 
[9] MARTIN V., LUMÍR H., ADAM B. (2016). Structural damping of mechanical vibration. In: Manufacturing Technology, Vol. 16, No. 6, pp. 1379-1382.

[10] LI Z. J., YANG X. J., CAI G. W., et al. (2010). Frequency reliability analysis of the runner blade of Francis turbine. In: Machinery Design \& Manufacture, No. 6, pp. 128-129.

[11] LI Z. J., LIU Y., LONG H., et al. (2013). Nonlinear vibration reliability of hydraulic turbinegenerator units with multiple failure modes. In: Journal of Mechanical Engineering, Vol. 49, No. 16, pp. 170-176.

[12] YUAN X. M., MA L., WU P., et al. (2013). Vibration analysis and optimization for upper bracket of high speed suspended hydro generator. In: Machine Design \& Research, Vol. 29, No. 6, pp. 108-111.

[13] LIAO Y. Y., LIAO B. Y. (2019). Lightweight optimization design of water turbine head cover based on maximum normal stress. In: Journal of Kunming University of Science and Technology (Natural Science), Vol. 44, No. 1, pp. 47-53.

[14] LIAO Y. Y., LIAO B. Y. (2019). Lightweight design of hydro generator upper bracket based on sizing optimization. In: Water Power, Vol. 45, No. 5, pp. 91-94, 117.

[15] LIAO Y. Y., LIAO B. Y. (2019). Finite element analysis and sizing optimization of hydro generator stator frame. In: Chinese Journal of Construction Machinery, Vol. 17, No. 3, pp. 215-220.

[16] YAMASAKI S., NISHIWAKI S., YAMADA T., et al. (2010). A structural optimization method based on the level set method using a new geometry-based re-initialization scheme. In: International Journal for Numerical Methods in Engineering, Vol. 83, No. 12, pp. 1580-1624.

[17] CHRISTENSEN P. W., KLARBRING A. (2009). An introduction to structural optimization. Springer, Dordrecht.

[18] DONG L. L., ZHU Y., NIU X. T., et al. (2010). Multi-objective topological optimization design of ultra-precision mechanical structure. In: China Mechanical Engineering, Vol. 21, No. 7, pp. 761-765.

[19] MARLER R. T., ARORA J. S. (2004). Survey of multi-objective optimization methods for engineering. In: Structural and Multidisciplinary Optimization, Vol. 26, No. 6, pp. 369-395. 